\title{
VARIATION IN THE NUMBER OF NUTRIENT FORAMINA IN LONG BONES OF LOWER LIMB IN CENTRAL INDIA
}

\author{
Rakate Nilesh S ${ }^{1}$, Gadekar Savita H ${ }^{* 2}$, Dhoot Mahesh B ${ }^{3}$.
}

${ }^{1}$ Assistant Professor, Department of Anatomy R.K.D.F Medical College hospital and Research Centre, Jatkhedi, Bhopal. M.P, India.

${ }^{2}$ Associate Professor, Department of Anatomy R.K.D.F Medical College hospital and Research Centre, Jatkhedi, Bhopal. M.P, India.

${ }^{3}$ Assistant Professor, Department of Anatomy R.K.D.F Medical College hospital and Research Centre, Jatkhedi, Bhopal. M.P, India.

\section{ABSTRACT}

Background: The major blood supply of long bone is from the nutrient arteries, these nutrient arteries enter the bone through a foramen called nutrient foramen. This is an opening into the shaft of a bone. Nutrient foramen gives passage to the blood vessels of the bone. The nutrient foramen has a particular position for every bone and the direction of foramen is away from growing end of bone.

Objective: The aim of the present study was to study the anatomy and morphology of the nutrient foramina in human lower limb long bones.

Materials and Method: The study was performed on 120 lower limb long bones which included 40 femur, 40 tibia and 40 fibula. The bones were obtained from department of anatomy, R.K.D.F Medical college hospital \& research centre and R.K.D.F Dental college \& hospital Bhopal.

Results: The variations were found in number and position of nutrient foramen in different lower limb long bones. Double and triple foramina were observed in femur. In few lower limb long bones nutrient foramen was absent.

Conclusion: The knowledge of these foramina is useful in orthopaedics certain operative procedures as well as in plastic and reconstructive surgery, to avoid harm to the nutrient artery.

KEY WORDS: Nutrient Foramen, Nutrient Artery, Femur, Tibia, Fibula.

Address for Correspondence: Dr. Savita Hemant Gadekar, Department of Anatomy R.K.D.F Medical College hospital and Research Centre, Jatkhedi, Bhopal. M.P 462026, India.

contact number-9826657118 E-Mail: drsavitagadekar@gmail.com

Access this Article online

Quick Response code

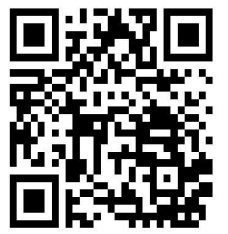

DOI: $10.16965 /$ ijar.2018.368

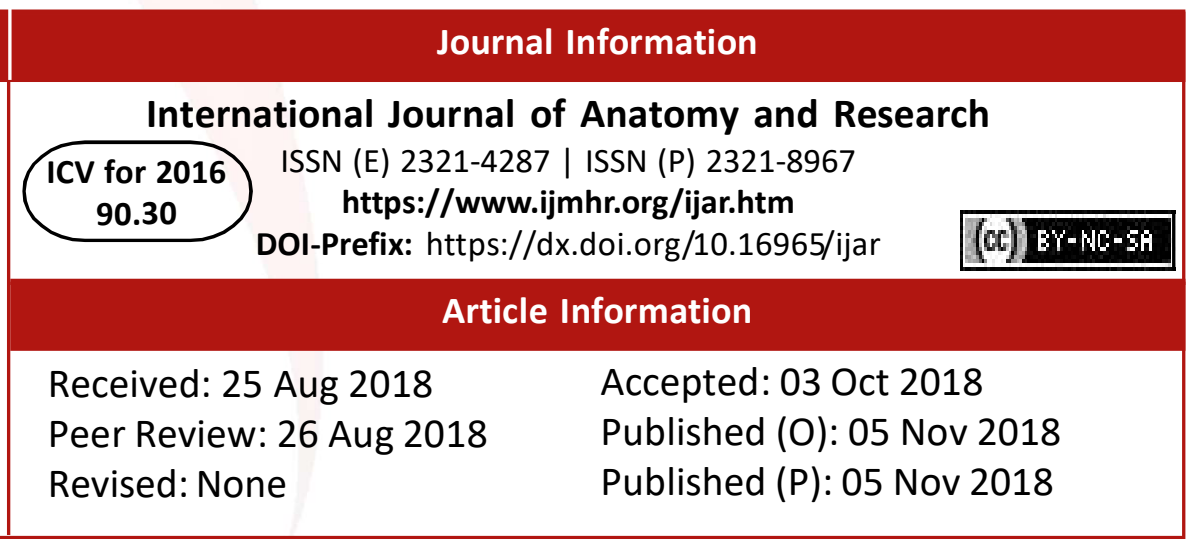

passes through nutrient foramina particularly during the active growing phase in the embryo and foetus, as well as during stages of ossification. [2-4]. The long bones receive about $80 \%$ of the interosseous blood supply from the nutrient arteries during childhood, and in their absence, 
periosteal vessels supply nutrition to the bones [5]. The blood supply of the long bones generally is carried by one or two diaphyseal nutrient arteries and numerous metaphysial and epiphysial arteries. The diaphyseal nutrient arteries penetrate obliquely in the diaphysis of the long bones, there location and angle being relatively constant dividing into ascending and descending branches [6]. The nutrient canal (through which nutrient artery passes within the shaft) typically become oblique during growth. The direction of the nutrient foramen of each bone is away from growing end [7]. The presence of distinct vascular groove outside the nutrient foramen makes it easily distinguished from other foramens on the bone. $[1,8]$ Each bone has a particular position for nutrient foramen [9].

The nutrient foramina in femur is directed proximally, positioned on the linea aspera varying in size and number, usually one was located near its proximal end and second at its distal end. The main nutrient artery is usually arises from 2nd perforating artery. If two nutrient arteries present, they may arises from 1st and 3rd perforators [10]. In tibia, a faint vertical line descends downwards from the centre of the soleal line, a vascular groove joins the end of this line and descends downwards into a nutrient foramen. The nutrient foramen usually lies below the soleal line and gives passage to a branch of the posterior tibial artery. The nutrient artery may also arise from the popliteal bifurcation or as a branch from the anterior tibial artery [10].

In fibula nutrient foramen is present a little above the midpoint of the posterior surface and is directed downwards. The vascular supply comes from the branch of the fibular artery [10-13]. A considerable interest in studying nutrient foramina resulted not only from morphological but also from clinical aspects. Some pathological conditions such as developmental abnormalities, acute hematogenic osteomyelitis or fracture healing are closely related to the vascular system of bone [14]. Longia GS et al observed in human long bone the nutrient foramina lies on the flexor aspect [15]. Studying the location and number of the nutrient foramina in long bones is therefore becomes more important in orthopaedic surgical procedures such as fracture repair, joint replacement therapy, bone grafts and vascularized bone microsurgery as well as medicolegal cases [16]. The aim of the present study was to study the anatomy and morphology of the nutrient foramina in human lower limb long bones.

\section{MATERIALS AND METHODS}

The study included 120 lower limb cadaveric long bones which included 40 femurs 20 right, 20 left), 40 tibiae (20 right, 20 left), 40 fibulae (20 right, 20 left). The bones were obtained from department of anatomy, R.K.D.F. Medical college hospital \& research centre and R.K.D.F. Dental college \& hospital, Bhopal. All the bones were observed carefully for number, location and direction of nutrient foramina. Nutrient foramina was identified easily by naked eyes by the presence of a groove leading to them and by a well marked often slightly raised, edge at the commencement of the canal. Only diaphyseal nutrient foramina were counted and studied in all the long bones. Foramina at the ends of the bones were not included in study. Each bone was divided into 3 parts (upper, middle, lower1/3rd) after measuring the length of bone for determining the topographical distribution of nutrient foramen along the length of the bones.

\section{RESULTS}

In case of femur $52.5 \%$ ( 21 out of 40 ) had single nutrient foramen, $22.5 \%$ (09 out of 40 ) had double foramina , $25 \%$ (10 out of 40 ) had triple foramina. Out of $52.5 \%$ femur ( 21 out of 40 ) nutrient foramen was located on the proximal part of linea aspera in $47.6 \%$ (10 out of 21 ). In $38 \%$ (08 out of 21) it was found medial to medial lip of linea aspera in its distal part. But in $14 \%$ ( 3 out of 21 ) it was observed on the distal part of linea aspera. In $22.5 \%$ femur (09 out of 40) showing double foramina the location of nutrient foramina was quite different. In $88.9 \%$ (08 out of 09), one nutrient foramen was located on the proximal part of linea aspera and another was located on the distal part of linea aspera. In $11.1 \%$ femur (1 out of 9) one nutrient foramen was located just below the spiral line and another was medial to medial lip in distal part.

In $25 \%$ of femur (10 out of 40 ) (Fig 1) showing triple foramina, upper nutrient foramen was 
located on gluteal tuberosity, middle one was on proximal part of linea aspera and lower one on the medial lip of linea aspera in distal part of it.

Fig. 1: Femurs showing triple nutrient foramina at different locations.

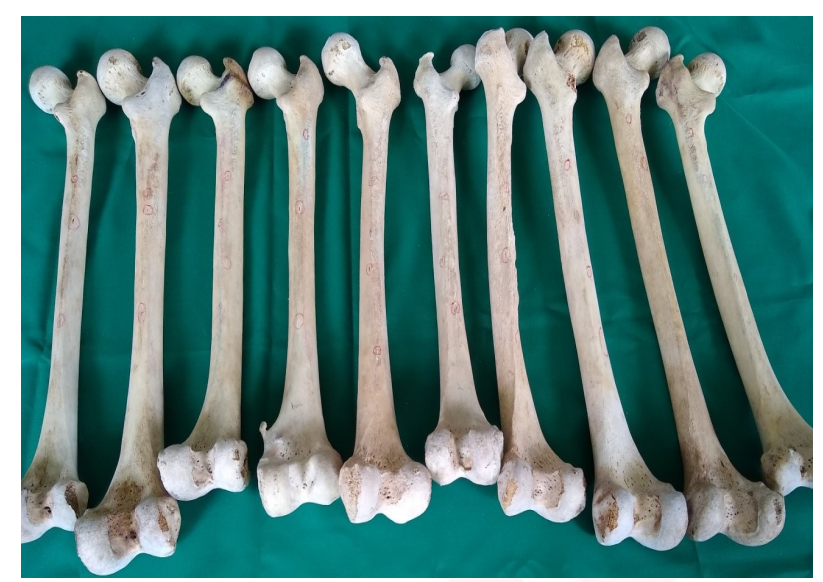

In case of tibiae, $95 \%$ tibiae (38 out of 40 ) had single nutrient foramen, out of these $92 \%$ tibiae (35 out of 38) shown nutrient foramen in relation to vertical line on the posterior surface of tibia(fig.2) and 8\% (3 out of 38) of cases the nutrient foramen was located near lateral border on posterior surface. The double nutrient foramina was found in remaining $5 \%$ tibiae $(2$ out of 40) one foramen was lying lateral to vertical line and another was located on the medial border at the middle of shaft.

Fig. 2: Tibia showing single nutrient foramen on vertical line.

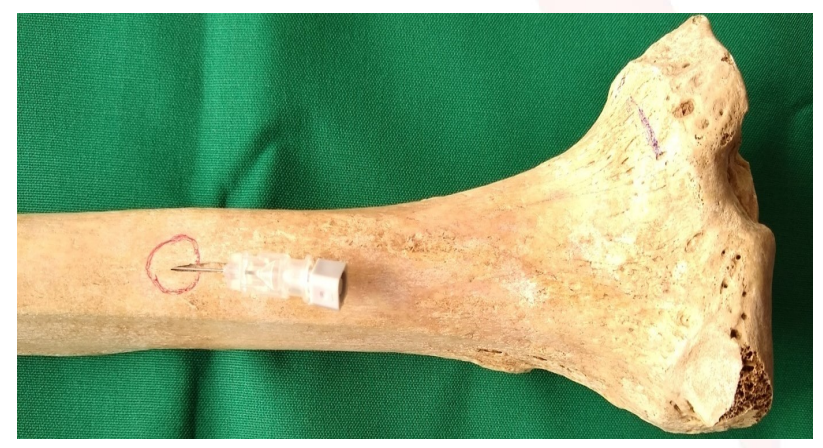

With respect to fibulae, we observed that $72.5 \%$ of fibulae (29 out of 40 ) shown single nutrient foramen. Out of which $55 \%$ of fibulae (16 out of 29) shown nutrient foramen in relation with posterior border and $45 \%$ ( 13 out of 29 ) of cases shown nutrient foramen in relation with medial border. The $25 \%$ of the fibulae ( 10 out of 40 ) (Fig 3 ) had found double nutrient foramen. Out of which $60 \%$ of fibulae (6 out of 10 ) had foramen located on the posterior border. The $20 \%$ of fibulae ( 2 out of 10 ) had 1 foramen on posterior surface, $10 \%$ of fibulae ( 1 out of 10 ) shown both the foramen located on medial border and $10 \%$ (1 out of 10) of fibulae shown both foramen located on medial surface. $10 \%$ of the cases (1 out of 10) shown 1 nutrient foramen on posterior border and 1 foramen on anterior surface. In the remaining $2 \%$ ( 1 out of 50 ) of the cases, triple nutrient foramen was observed and all 3 nutrient foramen was located on posterior border near the middle of the shaft. In the present study none of the fibulae found with the absence of nutrient foramen.

Fig. 3: Fibulae showing double nutrient foramen at different location.

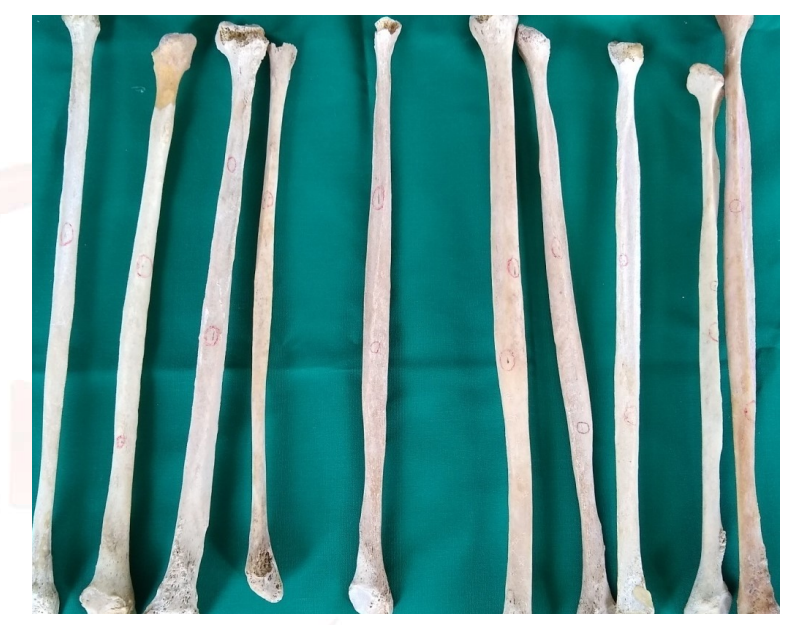

\section{DISCUSSION}

Many researcher reported that majority of femur studied had a single foramen in most specimen. [8,17-18]. Some researchers observed that the majority of femurs had double nutrient foramina[6,11] According to other researchers, the double nutrient foramen of femur was observed in $60 \%$,[2] 42.8\%,[19]46\%[20] and $55.6 \%$ cases.[21]Some authors found triple nutrient foramina in femurs. $[6,19]$ Some authors have observed multiple nutrient foramen up to 6 to 9 in their studies[20] while in some studies nutrient foramina was absent $[11,18]$.

In the previous studies have reported single nutrient foramen in $90 \%$ of the tibiae, they have reported the presence of double nutrient foramina in some of the tibiae $[13,18,26]$. In case of fibulae, single nutrient foramen was reported in $86.4 \%$, [13] 94\%, [22] 94.9\% [23] and $100 \%$. [2] The absence of nutrient foramina in long bones is well known [19, 24]. It was reported that in incidence where the nutrient foramen is 
absent, the bone is likely to be supplied by periosteal arteries [4]. In previous studies double nutrient foramen was observed in $11.7 \%$ cases [19] and triple foramina were observed in one fibula [13].

Hence the knowledge of nutrient foramen is important for orthopaedic surgeons preoperatively to preserve the circulation in open reduction of fractures, joint replacement therapies and in bone graft surgeries.

\section{Conflicts of Interests: None}

\section{REFERENCES}

[1] Mysorekar VR and nandedkar AN. Diaphyseal nutrient foramina in human phalanges. J Anat 1979;128: 315-22.

[2]. Forriol Campos F, Gomez Pellico L, Gianonatti Alias M, Fernandez- Valencia R. A study of the nutrient foramina in human long bones. Surg Radiol Anat 1987;9(3):251-255.

[3]. Lewis OJ. The blood supply of developing long bones with special reference to the metaphyses. J Bone Joint Surg 1956;38b: 928-933.

[4]. Patake SM and Mysorekar VR. Diaphysial nutrient foramina in human in human metacarpals and metetarsals. J Anat 1977;124:299-304.

[5]. Trueta J. Blood supply and the rate of healing of tibial fractures. Clin Orthop Rel Res 1953;105:1126.

[6]. Collipol E, Vergas R, Parra X, Silva H, Sol M. Diaphysial nutrient foramina in the femur, tibia and fibula bones. Int J Morphol2007;25(2):305-308.

[7]. Maulkar O, Joshi H. Diaphysial nutrient foramina in long bones. NJIRM 2011;2(2):23-26.

[8]. Lutken P. Investigation into position of nutrient foramen and direction of the vessel canal in the shaft of the humerus and femur in man. Acta Anat 1950;9:5768 .

[9]. Payton CG. The position of the nutrient foramen and direction of the nutrient canal in the long bones of the madder-fed pig. J Anat 1934;68(Pt4):500-510.

[10]. Gray H, William PL, Bannister LH. Bones. In: Williams PL editor. Gray's Anatomy. 38th ed. New York Churchill Livingstone;2000.p.1364,1415,1417.
[11]. Mysorekar VR. Diaphysial nutrient foramina in human long bones. J Anat 1967;101(4):813-822.

[12]. Taylor GI. Fibular transplantation. In: Serafin D, Bunke HJ editors. Microsurgical composite tissue transplantation. St Louis: CV Mosby Co; 1979.p.418423.

[13]. McKee NH, Haw P, Vettese T. Anatomic study of the nutrient foramen in the shaft of the fibula. Clin Ortop Relat Res 1984;184:141-144.

[14]. Skawina A, Wyczolkowski M.Nutrient foamen of humerus, radius and ulna in human fetuses. Folia Morphol1987;46:17-24.

[15]. Longia GS, Ajmani ML, Saxena SK, Thomas RJ. Study of diaphyseal nutrient foramina in human long bones. Acta Anat (Basel) 1980;107(4):399-406.

[16]. Rao VS, Kothapalli J. The diaphyseal nutrient foramina architecture - A study on the human upper and lower limb long bones. Journal of Pharmacy and Biological Sciences Jan 2014;9(1):36-41.

[17]. Bhatnagar S, Deshwal AK, Tripathi A. Nutrient foramina in the upper and lower limb long bones: $A$ Morphometric study in bones of western Uttar Pardesh. International Journal of Scientific Research 2014;3(1):301-3.

[18]. Al Motabagani MAH. The arterial architecture of the human femoral diaphysis. J Anat Soc India 2002;51:27-31.

[19]. Gumusburun E, Yucel F, Ozkan Y, Akgun Z. Astudy of the nutrient foramina of lower limb long bones. Surg Radiol Anat 1994;16:409-412.

[20]. Sendemir E, Cimen A. Nutrient foramina in the shafts of lower limb long bones: situation and number. Surg Radiol Anat1991;13:105-8.

[21]. Laing PG. The blood supply of the femoral shaft; an anatomical study. J Bone Joint Surg 1953;35:46266.

[22]. Restrepo J, Katz D, Gilbert A. Arterial vascularization of the proximal epiphysis and the diaphysis of the fibula. Int J Microsurg 1980;2:49-54.

[23]. Fen G. Fibular blood supply. Chin Med J 1981;94:396-400.

[24]. Kizilkanat E, Boyan N, Ozsahin ET, Soames R,Oguz O. Location, number and clinical significance of nutrient foramina in human long bones. Ann Anat 2007;189:87-95.

How to cite this article

Rakate Nilesh S, Gadekar Savita H, Dhoot Mahesh B. VARIATION

IN THE NUMBER OF NUTRIENT FORAMINA IN LONG BONES OF LOWER LIMB IN CENTRAL INDIA. Int J Anat Res 2018;6(4.2):58885891. DOI: 10.16965/ijar.2018.368 